e-Journal of Educational

Research, Assessment and Evaluation \section{REIIEVE}

Revista ELectrónica de Investigación y EValuación Educativa

\title{
ESTRATEGIAS DE APRENDIZAJE EN ESTUDIANTES UNIVERSITARIOS EXCELENTES Y MEDIOS. SU EVOLUCIÓN A LO LARGO DEL PRIMER AÑO DE CARRERA
}

\section{[Learning strategies in excellent and average university students. Their evolution over the first year of the career]}

\section{by/por}

Article record

$\underline{\text { About authors }}$

$\underline{\text { HTML format }}$

\author{
Gargallo, Bernardo (Bernardo.Gargallo@uv.es) \\ Almerich, Gonzalo (Gonzalo.Almerich@uv.es) \\ Suárez-Rodríguez, Jesús M. (jesus.m.rodriguez@uv.es) \\ García-Félix. Eloina (algarcia@ice.upv.es)
}

Ficha del artículo

$\underline{\text { Sobre los autores }}$

Formato HTML

\begin{abstract}
The aim of this paper was to analyze the evolution of learning strategies of two groups of students, excellent and average, from 11 degrees of the UPV (Valencia/Spain) in their freshman year. We used the CEVEAPEU questionnaire. The results confirmed the availability of better strategies of excellent students and also the existence of evolutionary patterns in which affective-emotional strategies decrease, such as value of the task or internal attributions, and that others increase, such as extrinsic motivation and external attributions. It seems that the student does not meet your expectations in the new context and professors have important responsibilities.
\end{abstract}

\section{Keywords}

University students; learning strategies; evolutionary study; excellent students; average students.

\begin{abstract}
Resumen
El objetivo de este trabajo era analizar la evolución de las estrategias de aprendizaje de estudiantes excelentes y medios de 11 titulaciones de la UPV (Valencia), en su primer año. Los alumnos contestaron el cuestionario CEVEAPEU en tres momentos. Los resultados constataron mejores estrategias en los estudiantes excelentes. También confirmaron patrones evolutivos en que estrategias afectivo-emotivas relevantes disminuyen, como valor de la tarea o atribuciones internas, y se incrementan otras, como motivación extrínseca y atribuciones externas. Parece que el estudiante no satisface sus expectativas en el proceso de adaptación al nuevo contexto y ahí los profesores tienen responsabilidades ineludibles.
\end{abstract}

\section{Descriptores}

Estudiantes universitarios; estrategias de aprendizaje; estudio evolutivo; estudiantes excelentes; estudiantes medios.

cksmith, 1987; Pozo, 1990; Weinstein y Danserau, 1985; Yip, 2012). Si bien es cierto que en determinados momentos el énfasis a la hora de conceptualizarlas se puso en los aspectos cognitivos y metacognitivos, también lo es que el concepto ha ido enriqueciendo su contenido 
hasta hacerse más integrador, incluyendo elementos afectivo-motivacionales y de apoyo.

Nosotros las entendemos como el conjunto organizado, consciente e intencional de lo que hace el aprendiz para lograr con eficacia un objetivo de aprendizaje en un contexto social dado integrando elementos afectivomotivacionales y de apoyo, metacognitivos y cognitivos. Son los tres componentes del modelo estratégico de Weinstein, Husman y Dierking (2000), "will", "self-regulation" y "skill", en que hay acuerdo básico entre los investigadores (Abascal, 2003; Ayala, Martínez y Yuste, 2004; Corno, 1994; García y Pintrich, 1991; Gargallo, 2000; GonzálezPumariega, Núñez Pérez, González Cabanach y Valle, 2002; Monereo, 1997; Yip, 2012).

Somos conscientes de que el concepto que proponemos es amplio y ecléctico. Sin embargo, nos decantamos por esta perspectiva frente a otras más restrictivas, ya que es más integradora y permite diseñar un mapa de estrategias más completo.

El concepto hay que entenderlo en una perspectiva dinámica, que ponga el énfasis en el uso "estratégico" de los diversos procedimientos que se movilizan para aprender. Las claves son la conciencia, intencionalidad, flexibilidad, manejo de recursos, vinculación al contexto y capacidad de supervisión y autorregulación -actuación metacognitiva, en definitiva(Kirby, 1984; Monereo, 1995).

El interés psicopedagógico del tema deriva de la incidencia de las estrategias de aprendizaje en el rendimiento académico (Camarero, Martín y Herrero, 2000; Cano y Justicia, 1993; Diset y Marthinsen, 2003; Gargallo et al., 2011; Gargallo, Suárez-Rodríguez y PérezPérez, 2009; Pintrich, 1995; Pintrich y García, 1991; Pintrich, Smith, García y Mackeachie, 1991; Roces et al., 1999; Soares, Guisande, Almeida y Páramo, 2009; Valle y Rodríguez, 1998; Yip, 2007, 2009 y 2012). Ello es así porque las estrategias de aprendizaje son uno de los constructos más potentes explicativos de los procesos de aprendizaje de los estudiantes.
Sin embargo, el tema ha sido muy poco abordado en el contexto a que hace referencia nuestra investigación, del análisis del perfil estratégico del estudiante excelente centrado en los primeros cursos de la universidad ${ }^{[1]}$. Yip (2007, 2009 y 2012) ha realizado varios estudios analizando las diferencias existentes en el uso de estrategias de aprendizaje, evaluadas mediante la escala LASSI, entre estudiantes con calificaciones altas y bajas de la Universidad de Hong Kong, usando el procedimiento de división por la media de las calificaciones para diferenciar estudiantes de alto y bajo rendimiento. Haciendo uso de ANOVA y de pruebas $t$ ha encontrado diferencias consistentes, fundamentalmente en las estrategias emotivo-afectivas y metacognitivas, a favor de los estudiantes con altas calificaciones. Resultados similares encontraron Proctor, Prevat, Adams, Hurst y Petscher (2006) en una universidad estadounidense, utilizando también la escala LASSI, el procedimiento de división por la media y haciendo uso de MANOVA.

También disponemos de estudios realizados sobre el funcionamiento de los estudiantes en su primer año universitario: analizando variables predictoras de un buen ajuste (Pritchard, Wilson y Yamnitz, 2007), impacto de la estructura familiar (Deronck, 2007), apoyo social y estrés académico (Rayle y Chung, 2007). Y encontramos estudios que analizan los factores que influyen en el rendimiento académico, de estudiantes nativos (Fore, 1998), o de estudiantes cuyos padres no fueron a la universidad (Strayhorn, 2006). Existen también investigaciones sobre rendimiento a lo largo de los estudios (De Miguel y Arias, 1999; Meléndez, 2007).

Dada la poca investigación existente en el tema que nos ocupa, nos centramos en las estrategias de aprendizaje de los estudiantes excelentes como elemento relevante de su perfil de aprendizaje. Los objetivos del presente estudio son estudiar la evolución de las estrategias de aprendizaje a lo largo del primer año en la universidad, a partir de tres tomas de datos realizadas durante éste, las diferencias 
existentes en este constructo entre dos colectivos de alumnos, excelentes y medios, y la evolución del mismo en los dos colectivos anteriormente aludidos. Nuestra hipótesis es que existirán diferencias significativas a favor de los estudiantes excelentes en manejo de estrategias de aprendizaje a lo largo del primer año. El análisis del perfil evolutivo de sus estrategias nos permitirá también extraer conclusiones relevantes de cara a la mejora del proceso de integración en la universidad y también a la mejora del rendimiento académico.

\section{Método}

\section{Diseño}

El presente estudio hace uso de un diseño cuasiexperimental longitudinal mixto, dado que se han tomado tres medidas en los dos grupos de estudiantes seleccionados, excelentes y medios, comparando los resultados de los dos colectivos y analizando también su evolución a lo largo del curso -diseño mixto- (Ato y Vallejo, 2007; Stevens, 2007).

\section{Participantes}

La muestra, que corresponde al final del tercer pase, está integrada por 217 alumnos, 124 excelentes y 93 medios, de la Universidad Politécnica de Valencia.

La extracción de la muestra se realizó mediante un muestreo no probabilístico de tipo intencional, considerándose dos criterios: titulación y tipo de estudiantes. La pretensión era obtener, por un lado, estudiantes de diversas titulaciones que pudiesen explicar la diversidad en las estrategias de aprendizaje a lo largo del tiempo, incorporando las variaciones debidas a las características propias de la titulación determinada. Por otro lado, en la selección de los grupos de estudiantes se optó por dos, excelentes y medios, con la finalidad de conseguir dos grupos que fueran representativos del rendimiento excepcional y el estándar de las diferentes titulaciones. Este enfoque resulta adecuado al objetivo ya que la definición de grupos más extremados en cuanto a rendimien- to no resulta particularmente viable en este caso.

Respecto al primero criterio, se seleccionaron 11 grupos de alumnos de 11 titulaciones ofrecidas en 9 centros. Estas titulaciones son: Ingeniero Técnico Industrial, Ingeniero Técnico en Diseño Industrial, Ingeniero Técnico en Informática, Ingeniero Técnico en Obras Públicas, Arquitecto Técnico, Arquitecto, Ingeniero de Telecomunicaciones, Ingeniero de Caminos, Canales y Puertos, Ingeniero Industrial, Licenciado en Bellas Artes, y Licenciado en Biotecnología.

En relación con el tipo de estudiantes se seleccionaron como sujetos excelentes ${ }^{[2]}$ los que habían obtenido las notas más altas en la Prueba de Acceso a la Universidad (PAU), estudiantes situados en el percentil 90 o superior en cada titulación. Como estudiantes medios fueron seleccionados los que se ubicaban alrededor de la mediana de la titulación, tomando como rango una desviación semiintercuartílica por encima y por debajo de dicho valor. De este modo, la nota de la PAU de los estudiantes excelentes es 8,7 y la de los medios es 7,3, encontrándose diferencias estadísticamente significativas entre ambos grupos $\left(\mathrm{t}_{273,567}=14,823 ; \mathrm{p}<, 000\right)$.

A partir de estos dos criterios, la muestra mínima proyectada durante los dos años de la investigación era de 10 alumnos excelentes y otros 10 medios por cada uno de los grupos, lo que daba un total de 220 alumnos. Sin embargo, dado que existían previsiones más que razonables de mortalidad experimental a lo largo de los dos años de la investigación, la muestra seleccionada inicialmente fue ligeramente mayor, acercándose a los 300 sujetos, de los que se obtuvo respuesta de 281 en el primer pase de instrumentos, de 236 en el segundo y de 217 en el tercero.

\section{Instrumento de recogida de la información}

El instrumento de recogida de la información es el Cuestionario de Evaluación de las Estrategias de Aprendizaje de los Estudiantes Universitarios (CEVEAPEU, Gargallo et al., 
2009). Consta de 88 ítems con respecto a los cuales el sujeto se pronuncia en una escala de $5 \operatorname{grados}^{[3]}$, en función de la valoración y/o uso del ítem correspondiente a la estrategia de que se trate. El cuestionario está organizado en dos escalas, seis subescalas y 25 estrategias.

$\mathrm{Su}$ estructura se recoge en el Cuadro I con los datos de fiabilidad correspondientes. Se recogen también en el cuadro las abreviaturas utilizadas. La fiabilidad de todo el cuestionario es de $\alpha=.897$. La fiabilidad de las veinticinco estrategias utilizadas en los análisis oscila entre .500 y .810 , aceptable dado el número de ítems de las mismas, que es pequeño en muchas de ellas.

\section{Procedimiento}

Los estudiantes seleccionados fueron informados del propósito de la investigación y animados a participar en la misma con una comunicación personal. Al inicio del primer cuatrimestre contestaron por primera vez el cuestionario junto a otros utilizados en la investigación, en este caso contextualizando la respuesta en su modo de proceder en el bachillerato, el curso anterior a su entrada en la universidad. Lo hicieron una segunda vez al inicio del segundo cuatrimestre y una tercera al finalizar éste, contextualizando sus respuestas en su modo de trabajar en ese primer año de universidad.
Se utilizó para responder el cuestionario la plataforma de e-learning de la Universidad Politécnica de Valencia (https://poliformat.upv.es/portal).

\section{Análisis estadísticos}

Los análisis estadísticos, realizados mediante SPSS 17.0, fueron descriptivos y un modelo ANOVA mixto para medidas repetidas, idóneo para examinar la interacción entre la evolución temporal de las estrategias y la pertenencia a uno de los dos grupos. Utilizamos las puntuaciones obtenidas por los estudiantes en las veinticinco estrategias de aprendizaje, lo que permitiría una aproximación más detallada y una mejor explicación que si tomábamos las puntuaciones de escalas o subescalas (Gráfico $1)$.

Modelos basados en ANOVA y MANOVA se han empleado recientemente en este ámbito para problemas similares (Yip 2009 y 2012; Proctor, et al. 2006). Esto permite no solamente determinar si existe un cambio a lo largo del periodo, sino que aporta información para la valoración cualitativa de este cambio al examinar la interacción entre la evolución temporal de las estrategias y la pertenencia al grupo.

(Continúa en página siguiente) 
Gargallo, Bernardo; Almerich, Gonzalo; Suárez-Rodríguez, Jesús M. \& García-Félix, Eloina (2012). Estrategias de aprendizaje en estudiantes universitarios excelentes y medios. Su evolución a lo largo del primer año de carrera.

RELIEVE, v. 18, n. 2, art. 1. DOI: $10.7203 /$ relieve.18.2.2000.

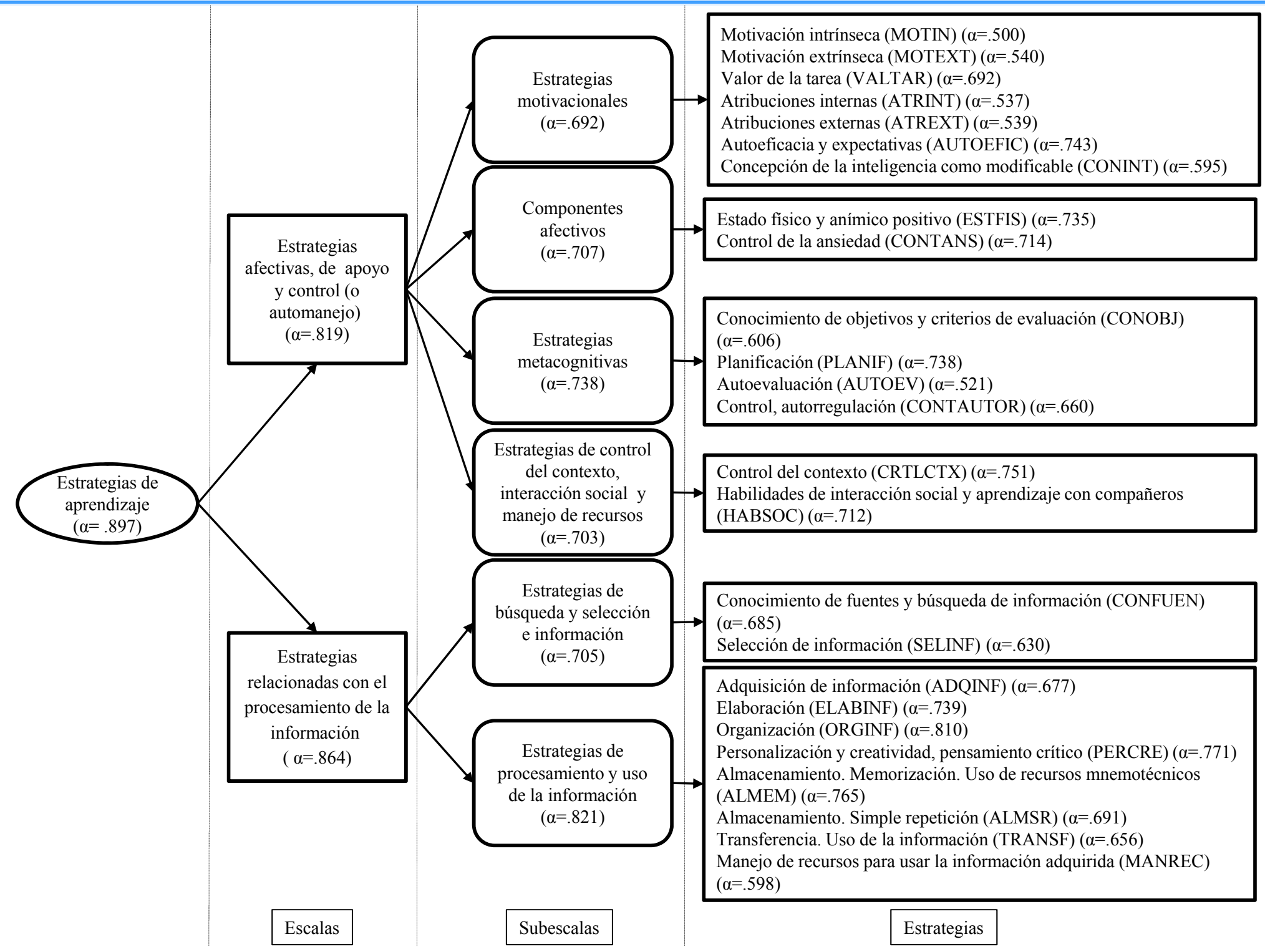

Cuadro 1 - Estructura del CEVEAPEU y datos de consistencia interna de las escalas 


\section{Resultados}

En este apartado, se presenta primero el análisis del modelo de medidas repetidas en función de los dos grupos de estudiantes, excelentes y medios. En segundo lugar la perspectiva multivariada respecto al perfil de las estrategias.

Para analizar la evolución de ambos grupos en las estrategias de aprendizaje en el primer año de la Universidad se ha utilizado un diseño mixto de medidas repetidas en función de los dos grupos, que contiene un factor intersujetos y un factor intrasujetos (Ato y Vallejo, 2007; Stevens, 2007). De esta forma, en primer lugar, se analizan las diferencias entre los estudiantes excelentes y los medios en las puntuaciones de las estrategias de aprendizaje -factor intersujetos-. En segundo lugar, se estudia la evolución que se produce en manejo de estrategias de aprendizaje en los tres momentos de medida -factor intrasujetos-. Finalmente, se expone la interacción entre la evolución temporal y el grupo de pertenencia de los estudiantes y se completa con la comprobación del modelo multivariado respecto al perfil de las veinticinco estrategias consideradas.

\section{Diferencias entre estudiantes excelentes y medios en el uso de estrategias en el primer año}

Los estudiantes excelentes obtienen una puntuación superior a los medios en veinte de las veinticinco estrategias (Tabla 1, Figura 1).

Se dan diferencias de medias estadísticamente significativas en doce de las veinticinco y en otras dos (atribuciones internas y conocimiento de fuentes) la diferencia está cercana al va- lor de significación de .05. La diferencia favorece a los estudiantes excelentes en valor de la tarea, autoeficacia, control de la ansiedad, planificación, autoevaluación, controlautorregulación, control del contexto, selección, adquisición de información y personalización-creatividad. Y a los medios en motivación extrínseca y almacenamiento-simple repetición. Esto último desmerece a los estudiantes medios, que manejan más estrategias de motivación extrínseca y de almacenamiento muy elementales (memorizar sin comprender por pura repetición).

Por lo que se refiere a los tamaños del efecto (a partir de la $\eta^{2}$ parcial) podemos afirmar que son mayoritariamente pequeños (Sink y Mvududu, 2010), aunque alcanzan valores moderados en motivación extrínseca y almacenamiento por simple repetición -a favor de los estudiantes medios-, y en control-autorregulación, con mayor nivel en los estudiantes excelentes.

Ello supone un mejor patrón estratégico en los estudiantes excelentes tanto en las estrategias afectivo-emotivas, de apoyo y control (motivacionales, afectivas, metacognitivas y de control del contexto) como en las de procesamiento y uso de la información (búsqueda y selección de información, y procesamiento y uso).

El mejor manejo estratégico de los estudiantes excelentes es relevante al incidir las estrategias en el rendimiento, como hemos vuelto a corroborar con los estudiantes de esta muestra (Gargallo et al., 2011), y ayuda a explicar el mejor rendimiento académico de los estudiantes excelentes. 
Gargallo, Bernardo; Almerich, Gonzalo; Suárez-Rodríguez, Jesús M. \& García-Félix, Eloina (2012). Estrategias de aprendizaje en estudiantes universitarios excelentes y medios. Su evolución a lo largo del primer año de carrera.

RELIEVE, v. 18, n. 2, art. 1. DOI: 10.7203/relieve.18.2.2000.

Tabla 1 - Diferencias en estrategias de aprendizaje entre excelentes y medios

\begin{tabular}{|c|c|c|c|c|c|c|c|}
\hline \multirow[b]{2}{*}{ Dimensiones } & \multicolumn{2}{|l|}{ Excelente } & \multicolumn{2}{|l|}{ Medio } & \multirow[b]{2}{*}{$F$} & \multirow[b]{2}{*}{ Significación } & \multirow[b]{2}{*}{$\eta^{2}$ parcial } \\
\hline & Media & $\begin{array}{c}\text { Desviación } \\
\text { típica }\end{array}$ & Media & $\begin{array}{c}\text { Desviación } \\
\text { típica }\end{array}$ & & & \\
\hline MOTIN & 4.09 & 0.46 & 4.00 & 0.45 & 1.93 & 0.166 & 0.01 \\
\hline MOTEXT & 2.32 & 0.76 & 2.75 & 0.76 & 16.31 & 0.000 & 0.07 \\
\hline VALTAR & 4.21 & 0.39 & 4.04 & 0.39 & 8.75 & 0.003 & 0.04 \\
\hline ATRINT & 4.10 & 0.40 & 3.99 & 0.40 & 3.60 & 0.059 & 0.02 \\
\hline ATREXT & 2.65 & 0.65 & 2.71 & 0.64 & 0.38 & 0.540 & 0.00 \\
\hline AUTOEFIC & 4.04 & 0.47 & 3.89 & 0.47 & 5.02 & 0.026 & 0.02 \\
\hline CONINT & 3.90 & 0.68 & 3.99 & 0.68 & 0.75 & 0.387 & 0.00 \\
\hline ESTFIS & 3.64 & 0.57 & 3.53 & 0.57 & 1.84 & 0.176 & 0.01 \\
\hline CONTANS & 3.22 & 0.76 & 2.91 & 0.76 & 7.98 & 0.005 & 0.04 \\
\hline CONOBJ & 3.72 & 0.51 & 3.63 & 0.51 & 1.67 & 0.197 & 0.01 \\
\hline PLANIF & 3.13 & 0.79 & 2.87 & 0.79 & 5.26 & 0.023 & 0.03 \\
\hline AUTOEV & 3.97 & 0.44 & 3.80 & 0.44 & 7.06 & 0.008 & 0.03 \\
\hline CONTAUTOR & 4.01 & 0.39 & 3.79 & 0.39 & 15.83 & 0.000 & 0.07 \\
\hline CRTLCTX & 3.84 & 0.56 & 3.67 & 0.56 & 4.63 & 0.033 & 0.02 \\
\hline HABSOC & 3.85 & 0.47 & 3.84 & 0.47 & 0.05 & 0.825 & 0.00 \\
\hline CONFUEN & 3.39 & 0.55 & 3.25 & 0.54 & 3.04 & 0.083 & 0.01 \\
\hline SELINF & 3.70 & 0.49 & 3.54 & 0.49 & 5.49 & 0.020 & 0.03 \\
\hline ADQINF & 4.23 & 0.45 & 4.09 & 0.45 & 5.17 & 0.024 & 0.02 \\
\hline ELABINF & 3.46 & 0.66 & 3.30 & 0.65 & 2.91 & 0.089 & 0.01 \\
\hline ORGINF & 3.39 & 0.83 & 3.51 & 0.83 & 1.11 & 0.292 & 0.01 \\
\hline PERCRE & 3.64 & 0.61 & 3.45 & 0.61 & 4.82 & 0.029 & 0.02 \\
\hline ALMEM & 3.49 & 0.67 & 3.45 & 0.67 & 0.13 & 0.723 & 0.00 \\
\hline ALMSR & 1.80 & 0.66 & 2.22 & 0.66 & 19.40 & 0.000 & 0.09 \\
\hline TRANSF & 3.89 & 0.49 & 3.78 & 0.48 & 2.68 & 0.103 & 0.01 \\
\hline MANREC & 3.62 & 0.65 & 3.46 & 0.65 & 2.67 & 0.104 & 0.01 \\
\hline
\end{tabular}

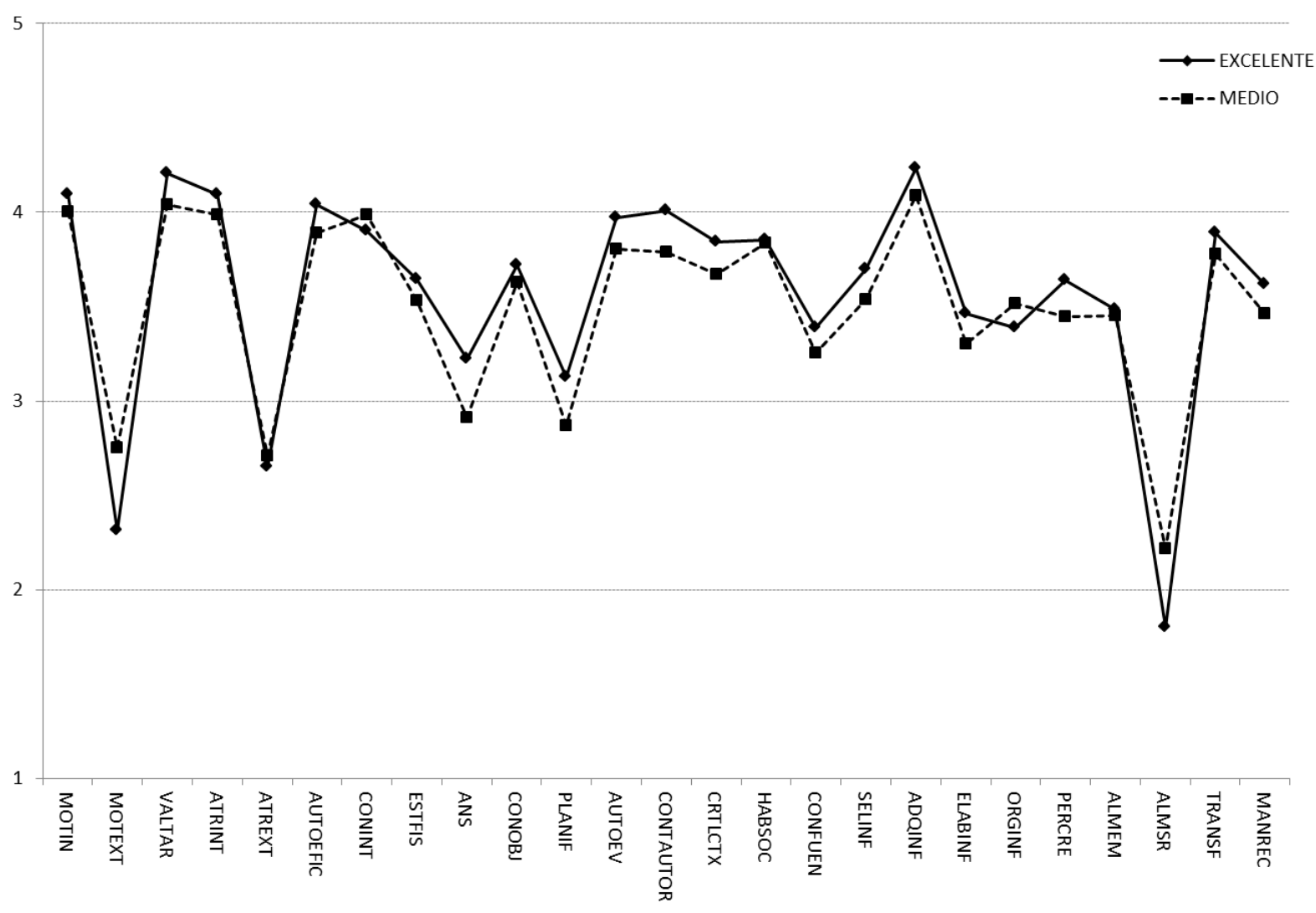

Figura 1 - Diferencias en estrategias de aprendizaje entre excelentes y medios 


\section{Evolución de las estrategias de aprendizaje en el primer año de ingreso en la universi- dad}

En dicha evolución se pueden considerar cuatro patrones distintos, definidos en función del uso de las veinticinco estrategias (Tabla 2 y Figura 2).

El primer patrón lo integran estrategias de aprendizaje que aumentan a lo largo del primer año. Son cinco: motivación extrínseca, atribuciones externas, habilidades de interacción social, conocimiento de fuentes y búsqueda, y elaboración de la información. Únicamente las habilidades de interacción no muestran diferencia estadísticamente significativa. De las otras cuatro, el conocimiento de fuentes y búsqueda es la estrategia con un tamaño del efecto mayor $(14,6 \%)$, existiendo una evolución constante en los tres momentos (Bonferroni). La motivación extrínseca crece a lo largo del año, produciéndose un incremento notorio en el segundo momento para bajar ligeramente en el tercero. En atribuciones externas la evolución es más marcada entre el primer y el segundo momento, manteniéndose el incremento en el tercero. Finalmente, en elaboración se da diferencia significativa entre el primer y el tercer momento, manteniéndose el crecimiento entre segundo y tercer momento. En tamaño del efecto estas tres últimas estrategias presen$\tan$ un valor pequeño, entre el 1,9\% y el 4,2\%.

El segundo patrón incluye estrategias que se mantienen casi sin variaciones. Son tres: motivación intrínseca -con ligero incremento entre el primer y el segundo momento-, control de la ansiedad y planificación, y no se dan diferencias significativas.

El tercer patrón integra estrategias que disminuyen. Son cinco: valor de la tarea, atribuciones internas, concepción de la inteligencia como modificable, adquisición de la información y almacenamiento-simple repetición. En todas se producen diferencias significativas entre los tres momentos con la excepción de atribuciones internas. Tanto en valor de la tarea como en concepción de la inteligencia co- mo modificable el cambio se produce sobre todo del segundo momento al tercero, aunque en ambas la diferencia es significativa entre el primer y el tercer momento (Bonferroni). En las otras dos estrategias, adquisición de la información y almacenamiento-simple repetición, el mayor descenso se produce entre el primer momento y el segundo -con ligera recuperación en adquisición de la información entre el segundo y el tercero-, encontrándose diferencias significativas en ambas entre el primero y segundo momento, y en almacenamiento entre el primero y tercero. El tamaño del efecto es pequeño, situándose entre el $1,9 \%$ y el $3,2 \%$.

El cuarto grupo incluye doce estrategias cuya evolución presenta un patrón en forma de $\mathrm{U}$, con reducción en el segundo momento y recuperación en el tercero. Salvo controlautorregulación, organización, y manejo de recursos, las restantes estrategias presentan diferencias estadísticamente significativas en los tres periodos. En estado físico y anímico, autoevaluación, control del contexto, selección de información, personalización y creatividad, almacenamiento-memorización y transferencia y uso el comportamiento es semejante, constatándose diferencias estadísticamente significativas entre la primera y la segunda medida y entre la segunda y la tercera (Bonferroni). La estrategia de autoeficacia y expectativas positivas únicamente presenta diferencia estadísticamente significativa entre el segundo y el tercer momento. En conocimiento de objetivos y criterios de evaluación la diferencia es estadísticamente significativa entre el primer y segundo momento y entre el primero y el tercero, manteniéndose el mismo patrón evolutivo que en las otras. En este grupo el tamaño del efecto es también pequeño en todos los casos - entre el 0,8\% y 4,2\%- (Sink y Mvudu$\mathrm{du}, 2010)$. 
Tabla 2 - Evolución de las estrategias de aprendizaje en el primer año

\begin{tabular}{|c|c|c|c|c|c|c|c|c|c|c|c|c|}
\hline \multirow[b]{3}{*}{ Dimensiones } & \multicolumn{6}{|c|}{ Momentos medida } & \multirow[b]{3}{*}{$F$} & \multirow[b]{3}{*}{ Sig. } & \multirow[b]{3}{*}{$\eta^{2}$ parcial } & \multicolumn{3}{|c|}{$\begin{array}{c}\text { Comparaciones por pares } \\
\text { (Bonferroni) }\end{array}$} \\
\hline & & $\mathrm{I}$ & & II & & III & & & & I-II & I-III & II-III \\
\hline & Media & $\begin{array}{l}\text { Desviación } \\
\text { típica }\end{array}$ & Media & $\begin{array}{l}\text { Desviación } \\
\text { típica }\end{array}$ & Media & $\begin{array}{l}\text { Desviación } \\
\text { típica }\end{array}$ & & & & Sig. & Sig. & Sig. \\
\hline MOTIN & 4.03 & 0.57 & 4.11 & 0.56 & 4.02 & 0.57 & 2.442 & 0.088 & 0.012 & 0.162 & 1.000 & 0.121 \\
\hline MOTEXT & 2.38 & 0.89 & 2.59 & 0.96 & 2.52 & 0.90 & 8.199 & 0.000 & 0.039 & 0.001 & 0.017 & 0.404 \\
\hline VALTAR & 4.20 & 0.50 & 4.16 & 0.56 & 4.06 & 0.52 & 5.395 & 0.005 & 0.026 & 1.000 & 0.007 & 0.059 \\
\hline ATRINT & 4.08 & 0.46 & 4.06 & 0.57 & 4.01 & 0.55 & 1.603 & 0.203 & 0.008 & 1.000 & 0.169 & 0.629 \\
\hline ATREXT & 2.53 & 0.75 & 2.72 & 0.85 & 2.77 & 0.78 & 8.847 & 0.000 & 0.042 & 0.009 & 0.000 & 0.865 \\
\hline AUTOEFIC & 4.01 & 0.56 & 3.91 & 0.64 & 4.02 & 0.57 & 3.670 & 0.026 & 0.018 & 0.190 & 1.000 & 0.027 \\
\hline CONINT & 4.01 & 0.81 & 3.94 & 0.83 & 3.86 & 0.85 & 3.885 & 0.021 & 0.019 & 0.878 & 0.014 & 0.292 \\
\hline ESTFIS & 3.67 & 0.68 & 3.50 & 0.70 & 3.62 & 0.62 & 8.850 & 0.000 & 0.042 & 0.000 & 1.000 & 0.000 \\
\hline CONTANS & 3.07 & 0.91 & 3.11 & 0.85 & 3.10 & 0.80 & 0.584 & 0.555 & 0.003 & 1.000 & 1.000 & 1.000 \\
\hline CONOBJ & 3.78 & 0.69 & 3.58 & 0.69 & 3.69 & 0.68 & 5.636 & 0.004 & 0.027 & 0.008 & 0.582 & 0.071 \\
\hline PLANIF & 3.00 & 0.91 & 3.03 & 0.86 & 3.03 & 0.90 & 0.282 & 0.755 & 0.001 & 1.000 & 1.000 & 1.000 \\
\hline AUTOEV & 3.93 & 0.55 & 3.83 & 0.55 & 3.94 & 0.56 & 5.071 & 0.007 & 0.024 & 0.038 & 1.000 & 0.013 \\
\hline CONTAUTOR & 3.94 & 0.50 & 3.88 & 0.53 & 3.93 & 0.50 & 2.307 & 0.101 & 0.011 & 0.257 & 1.000 & 0.257 \\
\hline CRTLCTX & 3.82 & 0.67 & 3.69 & 0.70 & 3.80 & 0.67 & 6.509 & 0.002 & 0.031 & 0.003 & 1.000 & 0.010 \\
\hline HABSOC & 3.79 & 0.56 & 3.86 & 0.58 & 3.88 & 0.57 & 2.833 & 0.062 & 0.014 & 0.358 & 0.098 & 1.000 \\
\hline CONFUEN & 3.12 & 0.72 & 3.42 & 0.62 & 3.46 & 0.63 & 34.473 & 0.000 & 0.146 & 0.000 & 0.000 & 0.000 \\
\hline SELINF & 3.68 & 0.66 & 3.55 & 0.56 & 3.66 & 0.53 & 6.839 & 0.001 & 0.033 & 0.004 & 1.000 & 0.004 \\
\hline ADQINF & 4.25 & 0.52 & 4.12 & 0.58 & 4.14 & 0.59 & 6.088 & 0.002 & 0.029 & 0.002 & 0.053 & 0.960 \\
\hline ELABINF & 3.31 & 0.82 & 3.43 & 0.76 & 3.44 & 0.80 & 3.965 & 0.021 & 0.019 & 0.088 & 0.048 & 1.000 \\
\hline ORGINF & 3.49 & 1.01 & 3.37 & 0.91 & 3.46 & 0.90 & 2.560 & 0.083 & 0.013 & 0.164 & 1.000 & 0.112 \\
\hline PERCRE & 3.59 & 0.71 & 3.48 & 0.69 & 3.60 & 0.74 & 5.933 & 0.003 & 0.029 & 0.029 & 1.000 & 0.005 \\
\hline ALMEM & 3.47 & 0.98 & 3.34 & 0.95 & 3.60 & 0.74 & 6.189 & 0.004 & 0.030 & 0.046 & 0.417 & 0.005 \\
\hline ALMSR & 2.08 & 0.89 & 1.93 & 0.79 & 1.91 & 0.79 & 6.665 & 0.002 & 0.032 & 0.018 & 0.006 & 1.000 \\
\hline TRANSF & 3.89 & 0.63 & 3.77 & 0.58 & 3.87 & 0.61 & 3.983 & 0.019 & 0.019 & 0.049 & 1.000 & 0.034 \\
\hline MANREC & 3.56 & 0.80 & 3.52 & 0.76 & 3.59 & 0.77 & 1.074 & 0.343 & 0.005 & 1.000 & 1.000 & 0.367 \\
\hline
\end{tabular}


Gargallo, Bernardo; Almerich, Gonzalo; Suárez-Rodríguez, Jesús M. \& García-Félix, Eloina (2012). Estrategias de aprendizaje en estudiantes universitarios excelentes y medios. Su evolución a lo largo del primer año de carrera.

RELIEVE, v. 18, n. 2, art. 1. DOI: 10.7203/relieve.18.2.2000.

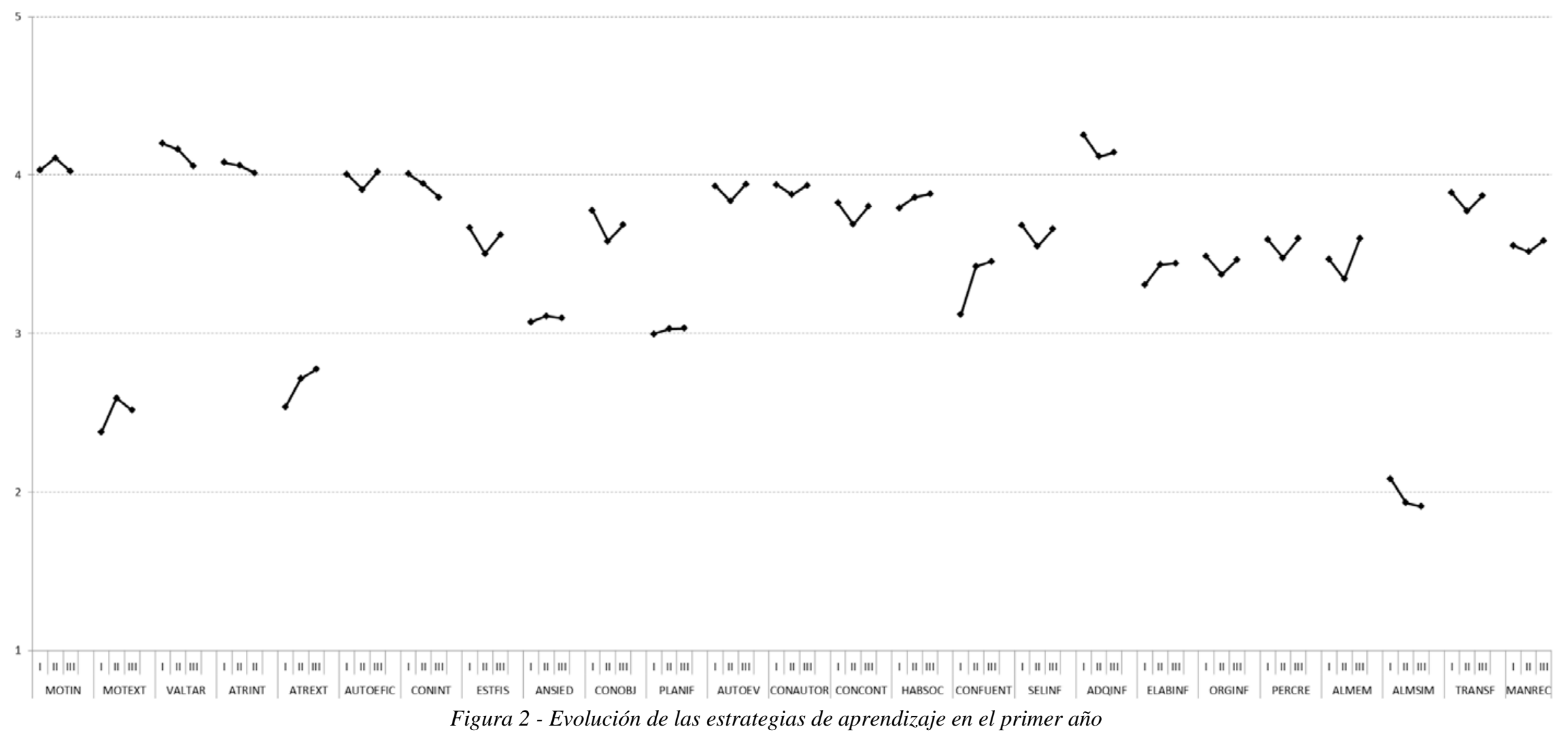

RELIEVE- Revista ELectrónica de Investigación y EValuación Educativa [ www.uv.es/RELIEVE] pag. 10 


\section{Evolución de las estrategias de aprendizaje analizando diferencias entre estudiantes excelentes y medios}

En este apartado se expone la interacción entre la evolución temporal de las estrategias en el primer año universitario y la pertenencia a uno de los dos grupos, excelentes y medios.

Los patrones antes descritos se reproducen a grandes rasgos en la interacción (Tabla 3 y Figura 3). Los estudiantes medios superan a los excelentes en cinco estrategias: motivación externa, atribución externa, concepción de la inteligencia como modificable, organización de la información y almacenamiento-simple repetición. Los estudiantes excelentes superan a los medios en las otras veinte, dándose diferencias significativas en control de la ansiedad, control del contexto y adquisición de información, estando personalización y creatividad cercano a $\mathrm{p}<.05$. Conviene reseñar las diferencias para ser conscientes del mejor manejo estratégico de los estudiantes excelentes.

Respecto a la evolución en los tres momentos, los cuatro patrones antes descritos también se constatan, con matizaciones.

Comentamos primero la evolución en las estrategias de la primera escala en que se den elementos relevantes.

En motivación extrínseca la evolución es semejante en ambos grupos y la distancia entre los medios y excelentes se mantiene, siendo mayor el incremento en los medios, sobre todo entre el primer y segundo momento.

En valor de la tarea se produce un descenso en ambos grupos en los tres periodos, siendo éste mayor en los estudiantes excelentes entre el segundo y tercer momento.

En atribuciones internas ambos grupos disminuyen, si bien es en el tercer momento y en los medios donde la bajada es mayor.

En atribuciones externas hay incremento en ambos grupos, mayor en los excelentes entre el primer y segundo momento, igualándose prácticamente en el tercero.

En autoeficacia se produce descenso en ambos grupos entre el primer y el segundo momento, recuperándose en el tercero. El grupo de estudiantes excelentes muestra mayores variaciones.

En concepción de la inteligencia como modificable ambos grupos mantienen un patrón decreciente, con un descenso más acusado en los medios en el tercer momento.

En control de la ansiedad el comportamiento de los dos grupos difiere: se da incremento entre el primer y segundo momento en los excelentes y ligero descenso en el tercero, experimentando los medios un aumento en el mismo periodo.

En conocimiento de objetivos y criterios de evaluación ambos grupos mantienen un comportamiento semejante en los tres momentos, siendo el incremento superior en los medios en la última medida.

En control-autorregulación el patrón es semejante, sufriendo los estudiantes medios una reducción entre el primero y el segundo para recuperarse en el tercero.

En control del contexto se produce un descenso en ambos grupos en el segundo momento de medida, mayor en los medios, recuperándose en el tercero.

Comentamos a continuación la evolución de las estrategias de la segunda escala.

En adquisición de la información el comportamiento de los grupos difiere. En los dos primeros momentos se produce un descenso en ambos. Del segundo al tercer momento los excelentes bajan mientras los medios suben.

En elaboración de la información el comportamiento también difiere. En los estudiantes excelentes se produce un incremento entre el primer y segundo momento, disminuyendo en 
el tercero. En cambio, los estudiantes medios presentan un incremento constante.

En personalización-creatividad se produce un descenso en ambos grupos entre el primer y segundo momento de la medida, para recuperarse en el tercero, siendo la intensidad del cambio mayor en los medios.

En transferencia y uso de la información ambos grupos presentan un comportamiento desigual. Entre el primer y el segundo momento se da descenso en ambos grupos, ligeramente superior en los excelentes. Entre el segundo $\mathrm{y}$ el tercero se produce una recuperación en ambos grupos siendo el incremento mayor en los medios.

Como se ha dicho antes, las interacciones han sido estadísticamente significativas en: ansiedad, control del contexto y adquisición de la información. En los tres casos el tamaño del efecto es pequeño (Sink y Mvududu, 2010).

\section{La perspectiva multivariada: comparacio- nes respecto al perfil de las estrategias}

Para la estimación de todos los efectos a nivel multivariado se ha tomado el indicador propuesto por Wilks.

En primer lugar, el perfil de las veinticinco estrategias de aprendizaje consideradas muestra una significación muy relevante en cuanto a la comparación de ambos grupos de estudiantes $\left(\mathrm{F}_{25,178}=2,539 ; \mathrm{p}<0.001 ; \eta^{2}\right.$ parcial $=$ $0,263)$. Por tanto, podemos afirmar que existe una diferencia global entre el perfil estratégico de ambos grupos de alumnos -con las concreciones ya señaladas anteriormente- y que el nivel del mismo es muy grande -aunque en este caso de indicadores multivariados suele dar valores mayores y no puede interpretarse en términos de proporción de la varianza explicada-.

En cuanto a la evolución temporal del perfil de estrategias de aprendizaje de los estudiantes a lo largo del primer curso de la carrera también se obtiene una significación muy alta $\left(\mathrm{F}_{50,153}=4,620 ; \mathrm{p}<0.001 ; \eta^{2}\right.$ parcial $\left.=0,602\right)$, que resulta perfectamente consonante con el mayor número de indicios significativos a nivel univariado. Podemos, pues, afirmar que se produce una evolución de las estrategias extremadamente consistente en el sentido de los patrones señalados a nivel univariado.

Finalmente, en cuanto a la evolución del perfil estratégico de los estudiantes en el primer año de carrera diferenciado para ambos tipos de estudiantes -efecto de interacción-, no se halla un efecto multivariado significativo $\left(\mathrm{F}_{50,153}=1,138 ; \mathrm{p}<0.420 ; \eta^{2}\right.$ parcial $\left.=0,253\right)$. Este hecho también es congruente con los menores indicios significativos que se han hallado a nivel univariado en este punto. No obstante, el tamaño del efecto hallado -aún con las consideraciones ya apuntadas más arriba- nos plantea la necesidad de profundizar en ello con una muestra más amplia y, posiblemente, con diferencias más extremadas entre los estudiantes comparados. 
Gargallo, Bernardo; Almerich, Gonzalo; Suárez-Rodríguez, Jesús M. \& García-Félix, Eloina (2012). Estrategias de aprendizaje en estudiantes universitarios excelentes y medios. Su evolución a lo largo del primer año de carrera.

RELIEVE, v. 18, n. 2, art. 1. DOI: 10.7203/relieve.18.2.2000.

Tabla 3 - Evolución de las estrategias de aprendizaje diferenciando alumnos excelentes y medios

\begin{tabular}{|c|c|c|c|c|c|c|c|c|c|c|c|c|c|c|c|}
\hline \multirow[b]{4}{*}{ Dimensiones } & \multicolumn{12}{|c|}{ Momentos medida } & \multirow[b]{4}{*}{$F$} & \multirow[b]{4}{*}{ Sig } & \multirow{4}{*}{$\begin{array}{c}\eta^{2} \\
\text { parcial }\end{array}$} \\
\hline & & & & & & & & & & & & & & & \\
\hline & \multicolumn{2}{|c|}{ Excelentes } & \multicolumn{2}{|c|}{ Medios } & \multicolumn{2}{|c|}{ Excelentes } & \multicolumn{2}{|c|}{ Medios } & \multicolumn{2}{|c|}{ Excelentes } & \multicolumn{2}{|c|}{ Medios } & & & \\
\hline & Media & DT & Media & DT & Media & DT & Media & DT & Media & DT & Media & DT & & & \\
\hline MOTIN & 4.08 & 0.58 & 3.96 & 0.54 & 4.15 & 0.59 & 4.05 & 0.52 & 4.04 & 0.60 & 3.99 & 0.53 & 0.315 & 0.730 & 0.002 \\
\hline MOTEXT & 2.24 & 0.85 & 2.58 & 0.90 & 2.37 & 0.88 & 2.91 & 0.97 & 2.34 & 0.77 & 2.77 & 1.02 & 1.504 & 0.223 & 0.007 \\
\hline VALTAR & 4.28 & 0.47 & 4.09 & 0.52 & 4.25 & 0.54 & 4.03 & 0.57 & 4.10 & 0.52 & 4.00 & 0.50 & 1.293 & 0.275 & 0.006 \\
\hline ATRINT & 4.11 & 0.48 & 4.03 & 0.44 & 4.10 & 0.55 & 4.01 & 0.60 & 4.08 & 0.55 & 3.92 & 0.53 & 0.583 & 0.559 & 0.003 \\
\hline ATREXT & 2.47 & 0.75 & 2.62 & 0.76 & 2.72 & 0.86 & 2.71 & 0.85 & 2.76 & 0.79 & 2.79 & 0.76 & 0.926 & 0.397 & 0.005 \\
\hline AUTOEFIC & 4.11 & 0.52 & 3.86 & 0.58 & 3.95 & 0.61 & 3.85 & 0.69 & 4.07 & 0.55 & 3.96 & 0.59 & 1.737 & 0.177 & 0.009 \\
\hline CONINT & 3.95 & 0.89 & 4.08 & 0.69 & 3.88 & 0.88 & 4.03 & 0.76 & 3.87 & 0.91 & 3.85 & 0.76 & 1.300 & 0.274 & 0.006 \\
\hline ESTFIS & 3.71 & 0.66 & 3.61 & 0.70 & 3.57 & 0.68 & 3.41 & 0.72 & 3.65 & 0.62 & 3.59 & 0.61 & 0.726 & 0.484 & 0.004 \\
\hline CONTANS & 3.23 & 0.91 & 2.85 & 0.87 & 3.26 & 0.83 & 2.90 & 0.84 & 3.17 & 0.79 & 2.99 & 0.81 & 3.093 & 0.046 & 0.015 \\
\hline CONOBJ & 3.85 & 0.69 & 3.67 & 0.69 & 3.63 & 0.68 & 3.51 & 0.70 & 3.68 & 0.69 & 3.70 & 0.67 & 1.748 & 0.175 & 0.009 \\
\hline PLANIF & 3.09 & 0.94 & 2.86 & 0.85 & 3.15 & 0.88 & 2.86 & 0.82 & 3.14 & 0.95 & 2.88 & 0.79 & 0.173 & 0.841 & 0.001 \\
\hline AUTOEV & 4.01 & 0.50 & 3.83 & 0.61 & 3.92 & 0.52 & 3.71 & 0.57 & 3.99 & 0.50 & 3.88 & 0.63 & 0.869 & 0.420 & 0.004 \\
\hline CONTAUTOR & 4.04 & 0.50 & 3.80 & 0.47 & 4.00 & 0.46 & 3.71 & 0.56 & 3.99 & 0.53 & 3.85 & 0.44 & 2.002 & 0.136 & 0.010 \\
\hline CRTLCTX & 3.88 & 0.67 & 3.75 & 0.67 & 3.82 & 0.64 & 3.51 & 0.75 & 3.84 & 0.71 & 3.76 & 0.61 & 3.591 & 0.028 & 0.017 \\
\hline HABSOC & 3.80 & 0.61 & 3.78 & 0.48 & 3.88 & 0.57 & 3.83 & 0.60 & 3.87 & 0.58 & 3.90 & 0.57 & 0.535 & 0.586 & 0.003 \\
\hline CONFUEN & 3.17 & 0.73 & 3.05 & 0.70 & 3.48 & 0.63 & 3.34 & 0.60 & 3.51 & 0.65 & 3.37 & 0.61 & 0.029 & 0.971 & 0.000 \\
\hline SELINF & 3.76 & 0.68 & 3.58 & 0.61 & 3.63 & 0.54 & 3.45 & 0.58 & 3.72 & 0.54 & 3.58 & 0.52 & 0.216 & 0.806 & 0.001 \\
\hline ADQINF & 4.34 & 0.53 & 4.14 & 0.48 & 4.21 & 0.53 & 3.99 & 0.62 & 4.15 & 0.67 & 4.13 & 0.46 & 3.522 & 0.030 & 0.017 \\
\hline ELABINF & 3.38 & 0.86 & 3.22 & 0.75 & 3.52 & 0.74 & 3.31 & 0.78 & 3.49 & 0.85 & 3.38 & 0.72 & 0.394 & 0.674 & 0.002 \\
\hline ORGINF & 3.44 & 1.05 & 3.55 & 0.96 & 3.33 & 0.97 & 3.44 & 0.82 & 3.40 & 0.98 & 3.56 & 0.78 & 0.117 & 0.889 & 0.001 \\
\hline PERCRE & 3.68 & 0.71 & 3.47 & 0.70 & 3.59 & 0.65 & 3.32 & 0.72 & 3.63 & 0.75 & 3.56 & 0.72 & 2.850 & 0.059 & 0.014 \\
\hline ALMEM & 3.45 & 1.07 & 3.50 & 0.85 & 3.38 & 0.97 & 3.30 & 0.93 & 3.63 & 0.75 & 3.56 & 0.72 & 0.548 & 0.579 & 0.003 \\
\hline ALMSR & 1.88 & 0.76 & 2.37 & 0.98 & 1.76 & 0.73 & 2.16 & 0.81 & 1.76 & 0.76 & 2.12 & 0.80 & 0.790 & 0.454 & 0.004 \\
\hline TRANSF & 3.97 & 0.65 & 3.77 & 0.58 & 3.82 & 0.59 & 3.71 & 0.55 & 3.88 & 0.64 & 3.86 & 0.57 & 2.151 & 0.118 & 0.011 \\
\hline MANREC & 3.63 & 0.80 & 3.45 & 0.79 & 3.59 & 0.77 & 3.41 & 0.74 & 3.63 & 0.76 & 3.53 & 0.78 & 0.425 & 0.654 & 0.002 \\
\hline
\end{tabular}

RELIEVE- Revista ELectrónica de Investigación y EValuación Educativa [ www.uv.es/RELIEVE ] 
Gargallo, Bernardo; Almerich, Gonzalo; Suárez-Rodríguez, Jesús M. \& García-Félix, Eloina (2012). Estrategias de aprendizaje en estudiantes universitarios excelentes y medios. Su evolución a lo largo del primer año de carrera.

RELIEVE, v. 18, n. 2, art. 1. DOI: 10.7203/relieve.18.2.2000.

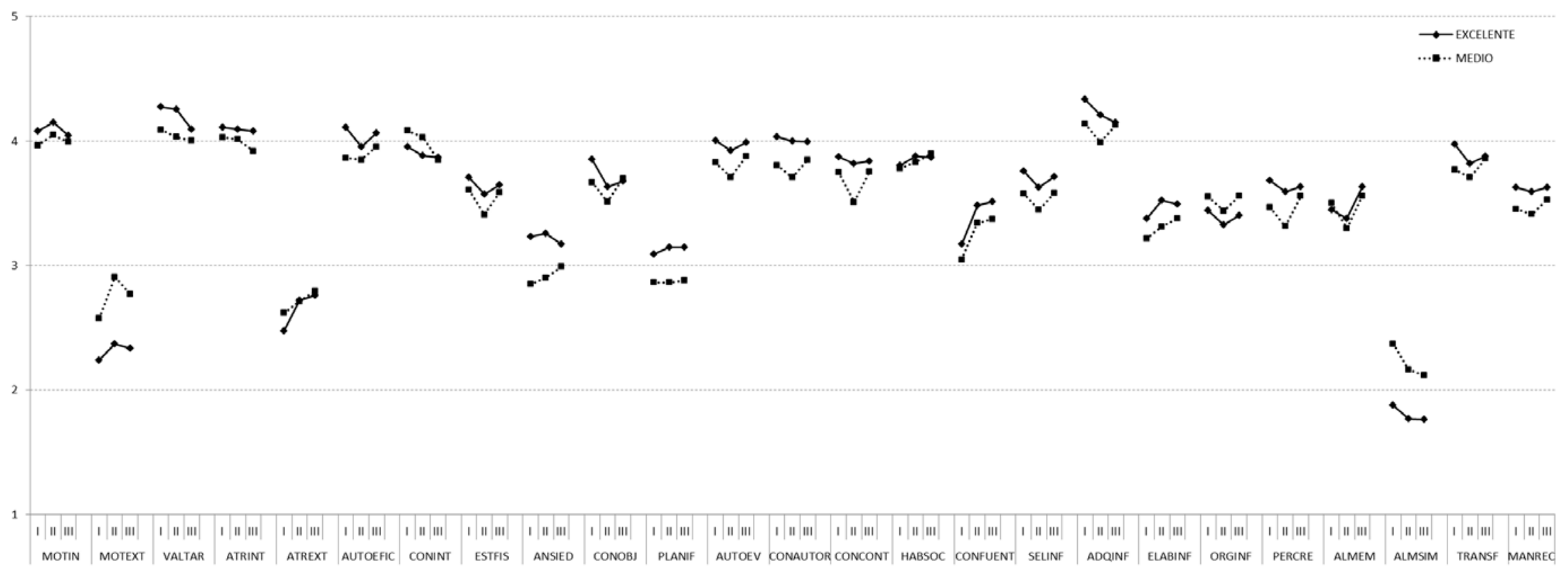

Figura 3 - Evolución de las estrategias de aprendizaje diferenciando alumnos excelentes y medios 


\section{Discusión y conclusiones}

Los resultados de este trabajo nos permiten constatar los objetivos formulados al inicio y establecer un perfil del estudiante universitario diferenciando entre alumnos excelentes y medios al analizar la evolución operada en las estrategias de aprendizaje a lo largo del primer año universitario. Los estudiantes excelentes se caracterizan fundamentalmente por un buen perfil estratégico, tomando puntuaciones globales del periodo, en el que predominan las estrategias de valor de la tarea, autoeficacia, control de la ansiedad, planificación, autoevaluación, control y autorregulación, control del contexto, selección de la información, adquisición y personalización/creatividad. Los estudiantes medios se caracterizan por un perfil estratégico más débil en el que destacan dos estrategias, motivación externa y almacenamiento-simple repetición. Ya comentamos antes que esto último no es positivo: la motivación es fundamental en el aprendizaje complejo y de calidad (Suárez, Fernández y Anaya, 2005; Castejón, Gilar y Pérez, 2006) y en el estudiante universitario debe primar la motivación intrínseca -que influye en el funcionamiento estratégico del estudiante (Gil, Bernaras, Elizalde y Arrieta, 2009; Yip, 2009 y 2012)- y el almacenamiento con comprensión.

Aunque el instrumento de medida difiere del utilizado por Proctor et al. (2006) y por Yip (2007, 2009 y 2012) hay coincidencia en que las diferencias, favorables a los estudiantes con altas calificaciones, se dan en los componentes "will" (elementos afectivomotivacionales) y "self-regulation" (elementos metacognitivos). En nuestro caso, aparecen también con claridad diferencias significativas en elementos del componente "skills" (habilidades y estrategias cognitivas de procesamiento).

Estos resultados permiten verificar en gran parte la hipótesis formulada relativa a las diferencias significativas favorables a los excelentes. Es verdad que, analizando la interacción entre la evolución temporal de las estrategias y la pertenencia al grupo de alumnos excelentes y medios las diferencias significativas se reducen sustancialmente, pero, aun así, los excelentes superan a los medios en la puntuación media de veinte de las veinticinco estrategias. Los resultados del análisis multivariado confirman las tendencias halladas en los obtenidos en el análisis univariado.

Por otra parte, se han hallado cuatro patrones distintivos de funcionamiento en estrategias de aprendizaje. El primero incluye estrategias que se incrementan a lo largo del primer año (motivación extrínseca, atribuciones externas, habilidades de interacción social, conocimiento de fuentes y búsqueda, y elaboración de la información). Vale la pena realizar una breve reflexión al respecto: no deja de ser llamativo que los alumnos incrementen su motivación extrínseca y sus atribuciones externas a lo largo del primer año, lo que debiera hacer pensar a los profesores universitarios docentes de primeros cursos sobre el papel a desempeñar y sobre su posible responsabilidad en este incremento de dos estrategias que tienen connotación negativa. Quizá los alumnos no encuentren el escenario que esperaban en las aulas universitarias y en la actuación de los profesores. Conviene reseñar, por otra parte, la mejora en las otras tres estrategias aludidas (habilidades de interacción social, conocimiento de fuentes y búsqueda, y elaboración de la información), lo que es positivo.

El segundo patrón integra estrategias que se mantienen (motivación intrínseca, control de la ansiedad y planificación). Las tres presentan connotaciones positivas. Teniendo claro que sólo la motivación intrínseca presenta una alta puntuación en ambos grupos, superior en los excelentes, y que el control de la ansiedad y la planificación sólo sobrepasan el valor medio de tres en los excelentes, por lo que hay amplio margen para la mejora.

El tercero patrón incluye estrategias que disminuyen (valor de la tarea, atribuciones internas, concepción de la inteligencia como modificable, adquisición de la información y 
almacenamiento/simple repetición). También parece relevante que empeoren estrategias motivacionales como el asignar valor a la tarea, hacer uso de atribuciones internas o considerar la inteligencia como modificable. Valdrían los mismos comentarios que hicimos con respecto al primer patrón. Es positivo, sin embargo, que disminuya el almacenamiento por simple repetición, pero no lo es que empeore la adquisición de información.

El cuarto patrón supone un retorno al momento inicial, pues entre el primer y segundo momento se produce una disminución de las estrategias que se incrementan al final del curso recuperando su estado inicial (lo que ocurre con autoeficacia y expectativas positivas, estado físico y anímico, conocimiento de objetivos y criterios de evaluación, autoevaluación, control-autorregulación, control del contexto, selección, organización, personalización y creatividad, almacenamiento y uso de recursos mnemotécnicos, transferencia y uso de la información, y manejo de recursos para usar la información). No deja de ser llamativo el hecho de que se produzca un empeoramiento en el uso de estrategias de aprendizaje en ese primer momento de medida si lo contrastamos con el modo de funcionar del curso anterior. Es verdad que luego las puntuaciones de estrategias se recuperan, al finalizar el primer año. Probablemente influya la transición que el estudiante experimenta de un entorno más conocido y controlado a otro menos conocido y complejo. Cuando el alumno consigue asentarse y adaptarse al nuevo entorno, las puntuaciones se recuperan. Hay que tener en cuenta que ello ocurre tanto en estrategias afectivoemotivas, de apoyo y control (autoeficacia, estado físico y anímico, conocimiento de objetivos y criterios de evaluación, etc.) como en estrategias de procesamiento de la información (selección, organización, personalizacióncreatividad, etc.). En todo caso, los profesores formamos parte de ese nuevo contexto y podemos y debemos actuar en consecuencia.

Somos conscientes de que en el aprendizaje de los alumnos y en su rendimiento influyen muchas variables: unas provenientes del estudiante, como motivos, intereses, actitudes, idiosincrasia personal, expectativas, experiencia previa, etc., y otras del contexto, como la naturaleza de las tareas, los propios contenidos de aprendizaje, la metodología de enseñanza y evaluación, etc. Sin embargo, no podemos dejar de remarcar la influencia de las estrategias de aprendizaje en el rendimiento académico. En este sentido los resultados que nosotros hemos obtenido analizando datos de la muestra del primer pase, recogidos en una publicación anterior (Gargallo et al. 2011), son similares a los aportados por Proctor et al. (2006) y por Yip (2007, 2009 y 2012), por referirnos a investigaciones recientes: son las estrategias de tipo afectivo-motivacional ("will") y las metacognitivas ("selfregulation") las que mejor predicen el rendimiento (análisis de regresión múltiple) y las que se asocian con los estudiantes excelentes de modo más marcado (análisis discriminante), sin desestimar tampoco el peso de algunas estrategias de procesamiento ("skills"), que aparecen en nuestros trabajos.

Como parte del contexto en que el estudiante aprende y en que desarrolla unas estrategias $u$ otras, los profesores influimos en cómo aprenden nuestros estudiantes y en cuánto aprenden. Aunque hay algunos datos de estudios que muestran mejoras en las estrategias de aprendizaje de los estudiantes utilizando programas específicos (Hernández Pina, Rosário, Cuesta, Martínez y Ruiz, 2006; Honkimäki y Tynjälä, 2007; Maehr y Yamaguchi, 2001; Tuckman y Kennedy, 2011), nosotros somos partidarios de trabajar de modo integrado la metodología docente en el aula para inducir cambios positivos. Tenemos datos de investigaciones que prueban que la metodología de enseñanza y evaluación del profesor influye significativamente en el modo de trabajar del estudiante (Biggs y Tang, 2007; Entwistle, 2009; Garga1lo, 2008; Gargallo, Garfella, Pérez y Fernández, 2010; Hounsell y Hounsell, 2007; McCune y Entwistle, 2011). Cuando los profesores suscriben planteamientos centrados en el aprendizaje y utilizan metodologías de ense- 
ñanza y evaluación adecuadas (nos referimos con ello al uso de métodos complementarios de los expositivos en la enseñanza, como la resolución de problemas, el estudio de casos, el uso de la pregunta, la discusión en clase, la elaboración de proyectos, el trabajo cooperativo, etc. que favorezcan la participación y el compromiso de los estudiantes, y a métodos formativos de evaluación que complementen a los sumativos y devuelvan feedback al alumno) (Smith, Douglas y Cox, 2009), los alumnos se decantan por el uso de más estrategias y de mayor calidad, al contrario de lo que ocurre cuando se suscriben planteamientos centrados en la enseñanza y cuando los profesores se centran en la metodología expositiva sin otras alternativas y en el examen final como método de evaluación, frente a otros procedimientos formativos. Si estos planteamientos se complementan con programas de acción tutorial y de acompañamiento en los primeros cursos, con docentes competentes y especialmente comprometidos, estamos convenidos de se puede mejorar el aprendizaje estratégico de nuestros estudiantes, su rendimiento en los primeros años de su camino universitario, que son críticos, y con todo ello potenciar la excelencia en la universidad. Éste es un trabajo a afrontar en ulteriores investigaciones.

\section{Referencias}

Abascal, J. (2003). El si mismo en los procesos de enseñanza-aprendizaje. En $\mathrm{M}^{\mathrm{a}}$.V. Trianes \& J.A. Gallardo (Coords.), Psicología de la educación y del desarrollo (pp. 496-522). Madrid: Pirámide.

Ato, M. \& Vallejo, G. (2007). Diseños experimentales en Psicología. Madrid: Pirámide.

Ayala, C.L., Martínez, R. \& Yuste, C. (2004). CEAM. Cuestionario de estrategias de aprendizaje y motivación. Barcelona: Instituto de Orientación Psicológica EOS.

Beltrán, J. (2003). Estrategias de aprendizaje. Revista de Educación, 332, 55-73.

Beltrán, J., Pérez, L.F. \& Ortega, M.I. (2006). CEA. Cuestionario de Estrategias de Aprendizaje. Madrid: TEA.
Bernad, J.A. (1999). Estrategias de aprendizaje. Madrid: Bruño.

Biggs, J.B. \& Tang, C. (2007). Teaching for Quality Learning at University (3rd Edition). Buckingham, UK: SRHE\&Open University Press.

Cabrera, L., Bethencourt, J.T., Álvarez, P. \& González, M. (2006). El problema del abandono de los estudios universitarios. Relieve, 12, 171-202.

Camarero, F., Martín, F. \& Herrero, J. (2000). Estilos y estrategias de aprendizaje en estudiantes universitarios. Psicothema, 12 (4), 615-622.

Cano, F. \& Justicia. F. (1993). Factores académicos, estrategias y estilos de aprendizaje. Revista de Psicología General y Aplicada, 46 (1), 89-99.

Castejón, J.L., Gilar, R. \& Pérez, A.M. (2006). Complex learning: The role of knowledge, intelligence, motivación and learning strategies. Psicothema, 18 (4), 679-585.

Corno, L. (1994). Implicit teachings and selfregulated learning. Comunicación presentada en el Annual Meeting of the American Educational Research Association. New Orleans, LA, April, 4-8.

Danserau, D.F. (1985). Learning Strategy Research. En H.F. O'Neil (Ed.), Learning Strategies (pp. 209-240). Nueva York: Academic Press.

De Miguel, M. \& Arias, J.M. (1999). La evaluación del rendimiento inmediato en la enseñanza universitaria. Revista de Educación, 320, 353-377.

Deronck, N.G. (2007). The impact of family structure and involvement on the college enrollment of potential first-generation college students. Dissertation Abstracts International Section A: Humanities and Social Sciences Vol. 68 (5-A), 2007, pp. 1827.

Diseth, Á. \& Martinsen, Ø. (2003). Approaches to learning, cognitive style, and motives and predictors of academic achievement. Educational Psychology, 23, 195-207.

Entwistle, N. (2009). Teaching for understanding at university: Deep approaches and dis- 
tinctive ways of thinking. Basignstoke, UL: Palgrave Macmillan.

Fore, Ch.L. (1998). Factors influencing academic achievement among Native American college students. Dissertation Abstracts International: Section B: The Sciences and Engineering Vol 58(8-B), pp. 4522.

García, T. \& Pintrich, P.R. (1991). Student motivation and self-regulated learning. Comunicación presentada en el Annual Meeting of the American Educational Research Association. Chicago, IL, April 3-7.

García, T. \& Pintrich, P.R. (1993). Selfschemas, motivational strategies and selfregulated learning. Comunicación presentada en el Annual Meeting of the American Educational Research Association. Atlanta, GA, April 12-16.

Gargallo, B. (2000). Procedimientos. Estrategias de aprendizaje. Su naturaleza, enseñanza y evaluación. Valencia: Tirant lo Blanch.

Gargallo, B. (2008). Estilos de docencia y evaluación de los profesores universitarios y su influencia sobre los modos de aprender de sus estudiantes. Revista Española de Pedagogía, 241, 425-446.

Gargallo, B., Garfella, P.R., Pérez, C. \& Fernández, A. (2010). Modelos de enseñanza y aprendizaje. Ponencia presentada en el XXIX Seminario Interuniversitario de Teoría de la Educación "Formación y participación de los estudiantes en la universidad". Madrid, Universidad Complutense, Noviembre. Recuperado el 20 de mayo de 2012, disponible en http://www.ucm.es/info/site/docu/29site/pone ncia3.pdf

Gargallo, B., García, E., Almerich, G., Garfella, P.R. Fernández, A. \& Rodríguez, Ma . C. (2011). Aprendizaje estratégico en estudiantes excelentes y en estudiantes medios. Bordón, 63 (4), 43-64.

Gargallo, B., Suárez-Rodríguez, J. M. \& Pérez-Pérez, C. (2009). El cuestionario CEVEAPEU. Un instrumento para la evaluación de las estrategias de aprendizaje de los estudiantes universitarios. RELIEVE, 15 (2), 1-31. Recuperado el 3 de mayo de 2012, disponible en

http://www.uv.es/RELIEVE/v15n2/RELIEV Ev15n2 5.htm

Gil, P., Bernaras, E., Elizalde, L.M. \& Arrieta, M. (2009). Estrategias de aprendizaje y patrones de motivación del alumnado de cuatro titulaciones del Campus de Gipuzkoa. Infancia y aprendizaje, 32 (3), 329-341.

González-Pumariega, S., Núñez Pérez, J.C., González Cabanach, R. \& Valle, A. (2002). El aprendizaje escolar desde una perspectiva psicoeducativa. En J. A. González-Pienda, R. González Cabanach, J.C. Núñez Pérez. \& A. Valle (Coords.), Manual de Psicología de la Educación (pp. 41-66). Madrid: Pirámide.

Hernández Pina, F., Rosário, P., Cuesta Sáez de Tejada, J.D. Martínez Clares, P. \& Ruiz Lara, E. (2006). Promoción del aprendizaje estratégico y competencias de aprendizaje en estudiantes de primero de universidad. Revista de Investigación Educativa, 24 (2), 615632

Honkimäki, S. \& Tynjälä, P. (2007). Study orientations in different tutoring environments: university language students' first two years. Mentoring \& Tutoring: Partnership in Learning, 15, 183-199.

Hounsell, D. \& Hounsell, J. (2007). Teachinglearning environments in contemporary mass higher education. En N.J. Entwistle y P.D. Tomlinson (Eds.), Student Learning and University Teaching. British Journal of Educational Psychology Monographs Series II, Number 4 (pp. 91-111). Leicester, UK: British Psychological Society.

Kirby, J.R. (1984). Cognitive strategies and educational performance. Orlando: Academic Press.

Maehr, M.L. \& Yamaguchi, R. (2001). Cultural diversity, student motivation and achievement. En F. Salili, C.Y. Chiu y Y.Y. Hong (Eds), Student Motivation: The culture and context of learning (pp. 123-148). Nueva York: Kluwer Academic/Plenum Publishers,

McCune, V. \& Entwistle, N. (2011). Learning and Individual Differences, 21, 303-310. 
Meléndez, D. (2007). Un ejercicio de evaluación de las trayectorias escolares en la Universidad de Guadalajara. Comunicación presentada en el $6^{\circ}$ Congreso Internacional Retos y Expectativas de la Universidad El papel de la universidad en la transformación de la sociedad. Recuperado el 25 de septiembre de 2011, disponible en http://www.congresoretosyexpectativas.udg. mx/Congreso 6/Eje 2/Ponencia 111.pdf

Monereo, C. (1995). De los procedimientos a las estrategias: implicaciones para el Proyecto Curricular Investigación y Renovación Escolar (IRES). Investigación en la escuela, 27, 21-38.

Monereo, C. (1997). La construcción del conocimiento estratégico en el aula. En $\mathrm{M}^{\mathrm{a}}$.L. Pérez Cabaní, La enseñanza y el aprendizaje de estrategias desde el currículum (pp. 2134).Gerona: Horsori.

Nisbet, J. \& Shucksmith, J. (1987). Estrategias de aprendizaje. Madrid. Santillana.

Pintrich, P.R. (1995). Understanding selfregulated learning. New Directions for Teaching and Learning, 63, 3-12.

Pintrich, P.R. \& García, T. (1991).Student goal orientation and self-regulation in the classroom. En M.L. Maher y P.R. Pintrich (Eds.), Advances in motivation and achievement. Vol. 7 (pp. 371-402). Greenwich, CT: JAI Press.

Pintrich, P.R., Smith, D. A. F., García, T. \& Mackeachie, W.J. (1991). A manual for the use of the Motivated Strategies for Learning Questionnaire (MSLQ). Ann Arbor: Universidad de Michigan. Technical Report No. 91B-004.

Pozo J.I. (1990). Estrategias de aprendizaje. En C. Coll, J. Palacios y A. Marchesi, Desarrollo psicológico y educación, II. Psicología de la educación (pp. 199-221). Madrid: Alianza.

Pritchard, M.E., Wilson, G.S. \& Yamnitz, B. (2007). What predicts adjustment among college students? A longitudinal panel study. Journal of American College Health, 56 (1), 15-21.
Proctor, B.E., Prevat, F., Adams, K., Hurst, A. \& Petscher, T. (2006). Study skills profiles of normal-achieving and academicallystruggling college students. Journal of College Students Development, 47 (1), 37-51.

Rayle, A.D. \& Chung, K. (2007). Revisiting first-year college students' mattering: Social support, academic stress, and the mattering experience. Journal of College Students Retention: Research, Theory and Practice, 9 (1), 21-37.

Roces, C., González-Pienda, J. A., Núñez, J. C., González-Pumariega, S., García, M ${ }^{a}$. S. \& Álvarez, L. (1999). Relaciones entre motivación, estrategias de aprendizaje y rendimiento académico en estudiantes universitarios. Mente y Conducta en Situación Educativa. Revista electrónica del Departamento de Psicología. Universidad de Valladolid, 1 (1), 41-50.

Sink, C.A. \& Mvududu, N.H. (2010). Statistical Power, Sampling, and Effect Sizes: Three Keys to Research Relevancy. Counseling Outcome Research and Evaluation, 1(2), 118. DOI: $10.1177 / 2150137810373613$

Smith, K.A., Douglas, T.C. \& Cox, M.F. (2009). Supportive teaching and learning strategies in STEM education. New Directions for Teaching and Learning, 117, 19-32.

Soares, A.P., Guisande, M.A., Almeida, L.S. \& Páramo, M. (2009). Academic achievement in first-year Portuguese college students: The role of academic preparation and learning strategies. International Journal of Psychology, 44 (3), 204-212.

Stevens, J.P. (2007). Intermediate Statistics: A Modern Approach. (3rd. ed.). Mahwah, NJ: Lawrence Erlbaum.

Strayhorn, T.L. (2006). Factors Influencing the Academic Achievement of First-Generation College Students, NASPA Journal, 43 (4), 82111.

Suárez, J.M., Fernández, A.P. \& Anaya, D. (2005). Un modelo sobre la determinación motivacional del aprendizaje autorregulado. Revista de Educación, 338, 295-306.

Tuckman, B.W. \& Kennedy, G.J. (2011). Teaching Learning Strategies to Increase 
Success of First-Term College Students. Journal of Experimental Education, 79, 478504.

Valle, A. \& Rodríguez, A. (1998). Estrategias de aprendizaje y rendimiento académico. Boletín de Psicología, 60, 27-53.

Weinstein, C.E. \& Danserau, D.F. (1985). Learning strategies: the how of learning. En J.W. Segal et al., Thinking and learning strategies (pp. 125-142). Hillsdale: Erlbaum.

Weinstein, C. E., Husman, J., \& Dierking, D. R., (2000). Interventions with a focus on learning strategies. En M. Boekaerts, P. R. Pintrich, \& M. Zeidner (Eds.), Handbook of Self-Regulation. (pp. 727-747) San Diego: Academic Press.

Wenstein, C.E., Zimmerman, S.A. \& Palmer, D.R. (1988). Assessing learning strategies: The design and development of the LASSI.
En C.E. Weinstein, E.T. Goetz y P.A. Alexander (Eds.), Learning and study strategies: Issues in assessment, instruction and evaluation (pp. 25-40). San Diego, CA: Academic Press.

Yip, M.C.W. (2007). Differences in learning and study strategies between high and low achieving university students: a Hong Kong study. Educacional Psychology, 27 (5), 597606.

Yip, M.C.W. (2009). Differences between high and low academic achieving university students in learning and study strategies: a further investigation. Educational Research and Evaluation, 15 (6), 561-570.

Yip, M.C.W. (2012). Learning strategies and self-efficacy as predictors of academic performance: a preliminary study. Quality in Higher Education, 18 (1), 23-34.

\section{NOTAS}

[1] Hemos elegido primer curso porque es un curso crítico en que el alumno se encuentra con un entorno nuevo que no domina: nueva organización, nuevos profesores, nuevos métodos, nuevos compañeros, etc. Además es el curso con mayor fracaso en la universidad (Cabrera, Bethencourt, Álvarez y González, 2006).

[2] Somos conscientes de que es cuestionable interpretar como estudiantes excelentes sólo los que obtienen las mejores calificaciones. Es una decisión del equipo investigador que tiene que ver con la necesidad de fijar parámetros lo más objetivos posibles para la clasificación, como lo son las notas académicas.

[3] Escala de puntuación: Muy en desacuerdo (1), en desacuerdo (2), indeciso (3), de acuerdo (4), muy de acuerdo (5).

Este trabajo es fruto del proyecto "La excelencia en los estudiantes universitarios desde un enfoque longitudinal: Análisis de factores incidentes y diseño de un modelo de intervención”, Programa Nacional de Proyectos de Investigación Fundamental, V Plan de Investigación Científica,

Desarrollo e Innovación Tecnológica (2010-2012) (Financiación Plan E, PGE) (código EDU2009/08518). 


\section{ABOUT THE AUTHORS / SOBRE LOS AUTORES}

Gargallo, Bernardo (Bernardo.Gargallo@uv.es). Catedrático de Teoría de la Educación de la Facultad de Filosofía y Ciencias de la Educación de la Universidad de Valencia. Es el autor de contacto para este artículo. Obtuvo el Primer Premio Nacional de Investigación Educativa en 2000 con un trabajo sobre estrategias de aprendizaje y también en 2002 con un trabajo sobre nuevas tecnologías y educación. Actualmente sus líneas prioritarias de investigación son las estrategias de enseñanza y de aprendizaje, y las nuevas tecnologías de la información y la comunicación (TIC) y su uso educativo. Su dirección postal: Facultad de Filosofía y Ciencias de la Educación. Avda. Blasco Ibáñez, 30; 46010-Valencia (España). Buscar otros artículos de este autor en Scholar Google

/ Find other articles by this author in Scholar Google

\section{Google}

Almerich, Gonzalo (Gonzalo.Almerich@uv.es). Profesor Contratado Doctor del Área de Métodos de Investigación y Diagnóstico en Educación de la Universidad de Valencia. Miembro de la Unidad de Tecnología Educativa en dicha universidad. Su dirección postal es: Facultad de Filosofía y CC. de la Educación. Avda. Blasco Ibáñez, 30. 46010-Valencia (España). Buscar otros artículos de este autor en Scholar Google / Find other arti-

cles by this author in Scholar Google

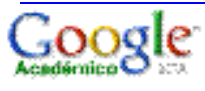

Suárez-Rodríguez, Jesús M. (jesus.m.rodriguez@uv.es). Catedrático de Métodos de Investigación en Educación de la Facultad de Filosofía y Ciencias de la Educación de la Universidad de Valencia. Fue Director de la revista RELIEVE hasta Junio de 2009. Es coordinador de la Unidad de Tecnología Educativa en la Universidad de Valencia. Su trabajo se centra en los elementos metodológicos, analíticos y de medición en los ámbitos de Ciencias Sociales y Salud. En los últimos años su línea de investigación prioritaria se centra en el impacto de las TIC en los diferentes niveles educativos. Su dirección postal: Facultad de Filosofía y Ciencias de la Educación. Avda. Blasco Ibáñez, 30. 46010-Valencia (España). Buscar otros artículos de este autor en Scholar Google /

Find other articles by this author in Scholar Google

$$
\text { Google }
$$

García-Félix, Eloina (algarcia@ice.upv.es). Asesora pedagógica en el Instituto de Ciencias de la Educación de la Universidad Politécnica de Valencia (UPV) y profesora asociada del Departamento de Métodos de Investigación y Diagnóstico en Educación, de la Universidad de Valencia. Su dirección postal es Facultad de Filosofía y Ciencias de la Educación. Avda. Blasco Ibáñez, 30. 46010-Valencia (España). Buscar otros artículos de esta au-

tora en Google Académico / Find other articles by this author in Scholar Google

\section{Google}


Gargallo, Bernardo; Almerich, Gonzalo; Suárez-Rodríguez, Jesús M. \& García-Félix, Eloina (2012). Estrategias de aprendizaje en estudiantes universitarios excelentes y medios. Su evolución a lo largo del primer año de carrera.

RELIEVE, v. 18, n. 2, art. 1. DOI: 10.7203/relieve.18.2.2000.

\section{ARTICLE RECORD / FICHA DEL ARTÍCULO}

\begin{tabular}{|c|c|}
\hline $\begin{array}{l}\text { Reference / } \\
\text { Referencia }\end{array}$ & $\begin{array}{l}\text { Gargallo, Bernardo; Almerich, Gonzalo; Suárez-Rodríguez, Jesús M. \& García-Félix, Eloina (2012). Estra- } \\
\text { tegias de aprendizaje en estudiantes universitarios excelentes y medios. Su evolución a lo largo del primer } \\
\text { año de carrera. RELIEVE, v. 18, n. 2, art. 1. DOI: } 10.7203 / \text { relieve.18.2.2000. }\end{array}$ \\
\hline Title / Título & $\begin{array}{l}\text { Estrategias de aprendizaje en estudiantes universitarios excelentes y medios. Su evolución a lo largo del } \\
\text { primer año de carrera. [Learning strategies in excellent and average university students. Their evolution } \\
\text { over the first year of the career]. }\end{array}$ \\
\hline $\begin{array}{l}\text { Authors / } \\
\text { Autores }\end{array}$ & Gargallo, Bernardo; Almerich, Gonzalo; Suárez-Rodríguez, Jesús M. \& García-Félix, Eloina. \\
\hline $\begin{array}{l}\text { Review / } \\
\text { Revista }\end{array}$ & RELIEVE (Revista ELectrónica de Investigación y EValuación Educativa), v. 18, n. 2 \\
\hline ISSN & $1134-4032$ \\
\hline $\begin{array}{l}\text { Publication } \\
\text { date / } \\
\text { Fecha de } \\
\text { publicación }\end{array}$ & $\begin{array}{l}2012 \text { (Reception Date: } 2012 \text { November 6; Approval Date: } 2012 \text { December 19; Publication Date: } 2012 \\
\text { December 19). }\end{array}$ \\
\hline \multirow{2}{*}{$\begin{array}{l}\text { Abstract / } \\
\text { Resumen }\end{array}$} & $\begin{array}{l}\text { The aim of this paper was to analyze the evolution of learning strategies of two groups of students, excel- } \\
\text { lent and average, from } 11 \text { degrees of the UPV (Valencia/Spain) in their freshman year. We used the CE- } \\
\text { VEAPEU questionnaire. The results confirmed the availability of better strategies of excellent students and } \\
\text { also the existence of evolutionary patterns in which affective-emotional strategies decrease, such as value } \\
\text { of the task or internal attributions, and that others increase, such as extrinsic motivation and external at- } \\
\text { tributions. It seems that the student does not meet your expectations in the new context and professors have } \\
\text { important responsibilities. }\end{array}$ \\
\hline & $\begin{array}{l}\text { El objetivo de este trabajo era analizar la evolución de las estrategias de aprendizaje de estudiantes excelen- } \\
\text { tes y medios de } 11 \text { titulaciones de la V (Valencia), en su primer año. Los alumnos contestaron el cuestiona- } \\
\text { rio CEVEAPEU en tres momentos. Los resultados constataron mejores estrategias en los estudiantes exce- } \\
\text { lentes. También confirmaron patrones evolutivos en que estrategias afectivo-emotivas relevantes disminu- } \\
\text { yen, como valor de la tarea o atribuciones internas, y se incrementan otras, como motivación extrínseca y } \\
\text { atribuciones externas. Parece que el estudiante no satisface sus expectativas en el proceso de adaptación al } \\
\text { nuevo contexto y ahí los profesores tienen responsabilidades ineludibles. }\end{array}$ \\
\hline $\begin{array}{l}\text { Keywords / } \\
\text { Descriptores }\end{array}$ & $\begin{array}{l}\text { University students; learning strategies; evolutionary study; excellent students; average students. } \\
\text { Estudiantes universitarios; estrategias de aprendizaje; estudio evolutivo; estudiantes excelentes; estudian- } \\
\text { tes medios. }\end{array}$ \\
\hline $\begin{array}{l}\text { Institution / } \\
\text { Institución }\end{array}$ & Universidad de Valencia y Universidad Politécnica de Valencia (España). \\
\hline \begin{tabular}{l|} 
Publication site \\
/ Dirección
\end{tabular} & http://www.uv.es/RELIEVE \\
\hline $\begin{array}{l}\text { Language / } \\
\text { Idioma }\end{array}$ & Español \& English Version (Title, abstract and keywords in English \& Spanish) \\
\hline
\end{tabular}

\section{RELIEVE}

\section{Revista ELectrónica de Investigación y $\mathbf{E V}$ aluación Educativa E-Journal of Educational Research, Assessment and Evaluation}

[ISSN: 1134-4032]

(C) Copyright, RELIEVE. Reproduction and distribution of this articles it is authorized if the content is no modified and their origin is indicated (RELIEVE Journal, volume, number and electronic address of the document).

(C) Copyright, RELIEVE. Se autoriza la reproducción y distribución de este artículo siempre que no se modifique el contenido y se indique su origen (RELIEVE, volumen, número y dirección electrónica del documento). 